\title{
Vida, naturaleza, y nihilismo afectivo en Fichte
}

\author{
Life, Nature and affective nihilism in Fichte
}

\author{
Vicente SERRANO \\ Universidad Austral de Chile
}

Recibido: 07-05-2012

Aceptado: 16-02-2013

\section{Resumen}

El artículo considera la obra de Fichte a partir de la noción de nihilismo, interpretándola sobre todo como una subordinación de la vida afectiva al imperativo moral. Tras su salida de Jena, Fichte habría intentado responder a las críticas de Jacobi, convirtiendo el concepto de vida en un tema central de su filosofía. El intento de conciliar esa dependencia del imperativo moral y la importancia dada a la vida a partir de las objeciones de Jacobi, permitiría entender algunas claves de su filosofía en el periodo de Berlín y en particular su concepción de lo absoluto.

Palabras clave: Absoluto, afectos, imperativo moral, Jacobi, nihilismo, vida.

\begin{abstract}
This paper considers Fichte's philosophy from the standpoint of the concept of nihilism: I contend that Fichte subordinates the emotional life to the moral imperative. After leaving Jena, Fichte would have tried to answer Jacobi's objections, making the concept of life his central philosophical concern. This attempt at reconciling the primacy of the moral imperative and a relevant concept of life (in response to Jacobi) would allow us to understand Fichte's philosophy in the Berlin period and, in particular, his concept of the absolute
\end{abstract}

Keywords: Absolute, Affects, Moral imperative, Jacobi, Nihilism, Life

Comenzaré por algunas aclaraciones en torno a los tres vocablos que aparecen en el título del artículo, a fin de explicitar la estrecha relación que guardan entre sí. La noción de nihilismo que cierra el rótulo es el término que mejor resume el reproche fundamental de Jacobi a la filosofía de Fichte en la carta pública que le dirige con motivo de la polémica sobre el ateísmo, y además con el acierto de ser capaz de condensar la mayor parte de las críticas en 
torno a la primera recepción de Fichte. Ciertamente Jacobi habla de nihilismo sin más, mientras que aquí caracterizamos y adjetivamos el nihilismo como afectivo, la explicación de lo cual constituye en gran parte el contenido y el objetivo del presente texto y está además estrechamente vinculada con los otros términos que aparecen: vida y naturaleza.Respecto de la naturaleza, es una obviedad recordar que ésta fue el principal motivo de disputa con Schelling, disputa en cuyo marco desarrolla Schelling su filosofía de la naturaleza y le objeta a Fichte su incapacidad para pensarla o desarrollarla. No nos interesa aquí, sin embargo, esa disputa, ni las razones de uno y otro, sino más bien su conexión con la cuestión del nihilismo, noción que, a su vez, se ha vinculado también a esa supuesta incapacidad de pensar la naturaleza, lo cual sin duda sería un aspecto, y tal vez el más visible, aunque desde luego no el que más interesaba a Jacobi al acuñar el término. En cuanto al tercero de los términos, la vida, lo traigo aquí en su acepción característicamente jacobiana que la contrapone a la especulación, partiendo de la premisa de que es en ella donde descansa el núcleo del reproche de nihilismo, pero también para ponerla en relación con uno de los debates cruciales de la interpretación e investigación de Fichte y que sigue hoy abierto, a pesar de la abundante literatura al respecto. Me refiero al problema del grado de ruptura del pensamiento fichteano a partir de la polémica sobre el ateísmo. Porque es poco discutible que el núcleo de ese debate tiene mucho que ver con la cuestión del supuesto subjetivismo y de manera explícita y notoria, por parte de Fichte, con las relaciones entre la vida y la especulación en los términos en lo que enmarca esta cuestión Jacobi.

Como es sabido, Fichte consideró que su filosofía fue siempre la misma, una filosofía de la libertad, y que sus distintas presentaciones obedecían al mismo principio. ${ }^{1}$ Igualmente negó en todo momento que su filosofía fuera incapaz de pensar la naturaleza o fuera atea. Y en ese orden de cosas, un argumento que nunca abandonó fue el carácter transcendental de su proyecto, un carácter transcendental que arruinaría los reproches respecto del acosmismo. Dedicó, sin embargo, un considerable esfuerzo a pensar las relaciones entre vida y especulación, a articularlas, hasta el punto de que la cuestión de la vida y sus relaciones con la especulación, además de ser objeto de una discusión metafilosófica ${ }^{2}$, o una cuestión cuya solución encomienda a la filosofía aplicada ${ }^{3}$, puede tenerse por uno de los centros nodales de su especulación posterior a Jena. Es un hecho que el propio Fichte hizo un considerable esfuerzo a fin de mostrar su compatibilidad con la filosofía transcendental y con su propio sistema, evidenciando así que esa cuestión de la vida, y no tanto la de la naturaleza o la del nihilismo en sí mismo considerado, fue el reproche que verdaderamente tuvo por significativo en la acusación de Jacobi. ${ }^{4}$ A partir de ahí, creo que es posible afirmar que cualquiera

\footnotetext{
${ }^{1}$ Cfr., Girndt, H. Die „Nova Methodo “ zwischen der Grundlage von 1794 und der Wissenschafstlehre 1804. En Fichte-Studien, 16, pp. 57-58.

2 Cfr., Zöller, G., Das Element aller Gewissheit. Jacobi, Kant, und Fichte über den Glauben. En: K Hammacher, Hrsg, Fichte- Studien, Bd. 14, p. 40.

3 Cfr., Österreich, P.L. Was geht auf dem langen Wege vom Geist zum System nicht alles verloren!. Jacobi und die angewandte Philosophie, En Fichte-Studien 14, pp. 153-170.

4 Así lo atestigua la proliferación de importantes trabajos, entre los que cabe citar el libro de comienzos de los 70 de Schrader, W. H., Empirisches und absolutes Ich. Zur Geschichte des Begriffs Leben in der Philosophie J.G. Fichtes, Stuttgart-Bad Cannsttat, Frommann Verlag, 1972, o los más recientes de Ahlers, R. Vitalism and system: Jacobi and Fichte on Philosophy and Life. En Idealistic Studies,
} 
que sea la interpretación que se haga de su filosofía posterior a la polémica, los principios de la misma, tanto en sus versiones populares como en las científicas, hacen casi irrelevante el reproche de acosmismo, e igualmente que la cuestión de la naturaleza a partir de Schelling no fue considerada por Fichte de peso suficiente, a diferencia de lo que ocurre con la vida, entendida ésta en los términos que desarrolla Jacobi. De hecho, ya interpretemos la filosofía de Fichte posterior a su salida de Jena en términos de regreso a una divinidad transcendente, o en términos de una filosofía que sigue siendo fiel al idealismo transcendental, la interpretación acosmista del nihilismo, que incluye tanto la imposibilidad de pensar el ser como la consiguiente incapacidad para obtener la naturaleza, resultan casi irrelevantes precisamente a partir de la vida misma como ese centro de sus intereses especulativos.

Desde esa perspectiva, si la cuestión del nihilismo en términos de Jacobi puede considerarse determinante para su evolución ha de serlo vinculada a la vida. ${ }^{5}$ Ésa es la objeción y es ahí donde Fichte considera que el problema del nihilismo le afecta y debe hacerle frente. Y a este respecto es importante destacar que el nihilismo, más allá de la cuestión del acosmismo, a la que se asocia la cuestión de la naturaleza y también la del ateísmo, no se determina en Jacobi sin más respecto de la posibilidad de no pensar la naturaleza, sino sólo de modo derivado, en la medida en que el nihilismo no permitiría pensar a Dios, según la conocida disyuntiva que plantea en la Carta a Fichte: O Dios o la nada6. Y ello en virtud de su planteamiento epistemológico, de su realismo, dependiente de la creencia en los términos que él ya había planteado antes en el David Hume. Por tanto el problema de fondo es el de Dios,y la naturaleza y el acosmismo, en el mejor de los casos, sólo derivados. Pero, a su vez, la cuestión, en los términos que la plantea Jacobi, es inseparable del problema de la vida, de la consideración de la especulación, contrapuesta a la vida, como un vacío, que es la otra forma de expresar el nihilismo. Son, pues, estas dos cuestiones las que le interesan a Fichte, la de la divinidad y la de la vida, cuestiones que no por casualidad van a aparecer en el contexto de la polémica sobre el ateísmo y serán reunidas en su filosofía de la religión de 1806, pero ya antes en la nuevas presentaciones científicas entre 1801 y 1805 y desde luego en $E l$ Destino del hombre.

Pero hay además una razón profunda, intrínseca a su propia trayectoria,para que fuera el tema de la vida, vinculado al de la divinidad, el que marcara de un modo tan notorio el pensamiento de Fichte y para que los reproches de Jacobi tuvieran una importancia en su pensamiento y en su obra que no tuvieron los de Schelling. Esa razón profunda está en los comienzos mismos de su obra, en los que precisamente la vida y la cuestión de la divinidad estaban ya estrechamente vinculadas. Y éste es el hilo conductor del que querría tirar aquí

Volume 33, 2003, pp. 83-113; Ivaldo, M. Wissen und Leben. Vergewisserungen Fichtes im Anschlußan Jacobi. En Friedrich Heinrich Jacobi. Ein Wendepunkt der geistigen Bildung der Zeit, Hamburg, Felix Meiner, 2004, pp. 53-74; oZöller, G. Das Element aller Gewisseit. Jacobi, Kant, und Fichte über den Glauben. En: K. Hammacher, Hrsg . Fichte- Studien, Bd. 14, pp. 21-43.

5 Traub, H. Über die Grenzen der Vernunft Das Problem der lrrationalität bei Jacobi und Fichte. En: K. Hammacher, Hrsg . Fichte- Studien, Bd. 14, p. 87-88.

${ }^{6}$ Cf., J..G. Fichte-Gesamtausgabe der Bayerischen Akademie der Wissenschaften, III, 3, 224-281. En lo sucesivo esa edición de las obras de Fichte será citada por las siglas GA, seguidas del número romano correspondiente a la serie y el arábigo al tomo correspondiente. Respecto de la Carta de Jacobi a Fichte hay edición en español a cargo de Vicente Serrano en Jacinto Rivera y Óscar Cubo (Editores), La polémica sobre el ateísmo. Fichte y su época. Madrid, Dykinson, 2009, pp. 503-544. 
para abordar los problemas que me he encomendado y para tratar de explicitar eso que he llamado nihilismo afectivo, pues esa noción de vida en Fichte, y especialmente vinculada a la divinidad, tiene ya en sus comienzos filosóficos prekantianos una importancia crucial que se expresa precisamente en las dimensiones emocional y sentimental, ambas asociadas a la vida.

De hecho la noción de vida es una constante explícita y un objeto privilegiado en toda su obra, con la única excepción del periodo inicial de Jena, precisamente el periodo que dio a conocer su obra y que ha moldeado durante décadas su recepción, y periodo en el que sin desaparecer del todo, no juega, al menos de forma expresa, el mismo rol destacado. Retrotraigámonos a sus inicios, antes incluso de haber alcanzado su propia concepción de la filosofía y de haber entrado en contacto con la filosofía de Kant, retrotraigámonos a un jovencísimo Fichte que, en la estela de las polémicas en torno a la religión en el seno de la Ilustración, está buscando el núcleo de la pedagogía de las doctrinas religiosas y de lo que él llama entonces la religión del corazón. ${ }^{7}$ Para el joven Fichte la cuestión era precisamente alejarse de las especulaciones de los filósofos y poder comprender mediante una dimensión afectiva las verdades de la religión, que es lo que se condensa en la expresión religión del corazón acuñada en el escrito Sobre las intenciones de la muerte de Jesús. En cierto modo podría decirse que ése es el germen del talante mismo del impulso filosófico inicial fichteano. Y es llamativo que ese talante se forje precisamente allí donde el objetivo es ir más allá de la especulación para movilizar lo que en ese momento llama Fichte el hombre completo $^{8}$. En realidad, ése es también el sentido de su recuperación de la vida cuando reaparece con nueva fuerza en su filosofía en el contexto de la polémica sobre el ateísmo. Fichte se había sentido especialmente cerca de las posiciones de Jacobi y así se lo había hecho saber ya desde agosto del 1795, convencido de una "llamativa concordancia" entre ambos $^{9}$, por lo que no podía dejar de dolerle el reproche de haber caído en la especulación muerta, es decir, en aquello que él mismo había combatido desde sus primeros años y que combatirá incansablemente hasta sus últimos días. Por ello en los años siguientes a la polémica, tanto en las versiones populares de su filosofía, primero en El Destino del hombre y luego en la Iniciación a la vida Bienaventurada, como en las presentaciones científicas, la vida se convierte ya en ese núcleo mismo de su pensamiento.

Sin embargo, aunque no es casual que esa reaparición de la vida lo sea vinculada al tema de la religión y de la divinidad, como lo era ya en los comienzos, si comparamos esas primeras manifestaciones de la vida con las posteriores a la polémica, descubrimos un pequeño matiz que genera grandes diferencias, matiz que descansa en la dimensión emocional. En la medida en que no hay todavía en el joven Fichte una teoría de los afectos vinculada al respeto kantiano por la ley moral, ni a la noción de sentimiento dependiente de ello, esa dimen-

\footnotetext{
7 Sobre la cuestión sigue siendo una referencia la obra de Preul, R. Reflexion und Gefühl. Die Theologie Fichtes in seiner vorkantischen Zeit. Berlin. Walter de Gruyter, 1969.

8 GA, II, 1, 87. Expresión que, aunque algo diversa, es muy próxima y de manera notoria a la gesammeltes Leben que habría sido el tema decisivo de Jacobi. Cfr., J.L. Villacañas, Nihilismo, especulacón $y$ cristianismo en F.H. Jacobi. Barcelona, Anthropos, 1989, p. 41.

9 Cf., Ivaldo, M., o.c., p. 55. En el mismo sentido Lauth, R. Fichtes Verhältnis zu Jacobi unter besonderer Berücksichtigung der Rolle Friedrich Schlegels in dieser Sache. In: Friedrich Heinrich Jacobi. Philosoph und Literat der Goethezeit, hg. v. Klaus Hammacher, Frankfurt a. M. 1971, p.165.
} 
sión afectiva debe entenderse como vinculada a la vida emocional en el sentido más ordinario del término. Las alusiones que Fichte nos da en el contexto de la pedagogía son bien reveladoras al respecto, puesto que es la posibilidad misma de que el niño o el joven incorpore todas sus dimensiones emocionales la que hace posible y deseable esa religión del corazón alejada de las especulaciones de los filósofos. Por lo demás es indudable que la religión está siempre vinculada a esas dimensiones afectivas y emocionales, a diferencia de lo que ocurre con la religión de los filósofos, que es en el fondo la que combate Fichte polémicamente frente a Reimarus. 10

Las cosas cambian, sin embargo, tras su salida de Jena. Ciertamente desde el punto de vista formal la vida recupera la misma función, y desde luego también vinculada a la cuestión religiosa o incluso a una teoría general de los afectos, en la que el amor reaparece como afecto fundamental para incluso fundirse con la propia vida, tal como se expresa en la Iniciación a la vida bienaventurada o en la Doctrina de la ciencia de 1804.Un punto de partida ineludible para abordar el análisis de ese tránsito es el texto clásico y tantas veces citado de 1799, por tanto en plena polémica, donde Fichte afirma que la vida no es filosofía y la filosofía no es vida11. Una concesión como esa habría zanjado la cuestión si no fuera porque el pensamiento posterior de Fichte no encaja plenamente con ella, y hace necesario interpretarla. Hecha en el fragor de la batalla podría significar simplemente una especie de paso hacia atrás para dar después dos hacia delante. Este texto es una directa respuesta, aunque provisional, a las objeciones de Jacobi y al rótulo de Mesías de la especulación recogido en su famosa carta donde le acusa de nihilismo. En cierto modo podría pensarse que es una reacción inicial ante la sorpresa de que Jacobi le hubiera malinterpretado de ese modo, sorpresa que en gran medida corre paralela a la que le produjo la acusación de ateísmo. Si nos atenemos a su correspondencia con Jacobi, Fichte no puede creer que su doctrina sea considerada tal cosa, como tampoco que lo que él esté haciendo no tenga que ver con la vida, a pesar de la forma científica que le da. De hecho más bien parece convencido de todo lo contrario, de que ha logrado presentar la vida por medio de la especulación y de la filosofía transcendental, cuya máxima culminación había llamado Doctrina de la ciencia. ${ }^{12}$ Algo que de hecho ya había expresado a Jacobi en su carta de 30 agosto del 96 al mencionar una reconciliación completa del punto de vista de la especulación y de la vida. ${ }^{13}$ Tras la polémica se verá entonces obligado a explicitar aún más y mejor la cuestión, a replantear las relaciones entre especulación y vida en otros términos, dando lugar desde luego a una metafilosofía, pero a la vez a una nueva expresión de esa coordinación y armonía, cuya formulación religiosa se plasma en un escrito popular como la Iniciación a la vida bienaventurada. Allí, después de haber establecido la fusión entre Dios y vida divina como la premisa misma del escrito, puede leerse: "brevemente, la reflexión transformada en amor divino y por esta misma razón aniquilada ella misma en Dios, es el punto de vista de la ciencia"14,

\footnotetext{
10 Cfr., Preul, o.c., p. 32.

11 Fichtes Werke, herausgegeben von Immanuel Hermann Fichte. Berlin, Walter de Gruyter, V, 343. En lo sucesivo citado mediante las siglas FW, seguido del número latino indicando el volumen correspondiente.

12 FW, V, 344-345.

13 GA, III, 2, 392.

$14 \mathrm{FW}, \mathrm{V}, 542$.
} 
afirmación especialmente significativa en un contexto en el que Dios se identifica para Fichte con la vida misma y el amor.

Pero ésa es la misma conclusión que podría hallarse dos años antes en una presentación científica, en la Doctrina de la ciencia de 1804: "tenemos que probar esto: únicamente porque el ser del saber absoluto es generable sólo genéticamente, y porque es esto bajo la condición precisa de semejantes determinaciones del saber, tal como las encontramos originalmente en la vida; únicamente por esto la vida está inseparablemente conectada a la Doctrina de la ciencia y a lo que ella genera. Y cada uno tiene que reconocer que toda su vida es nada, es sin valor ni significación, y propiamente carece en absoluto de existencia, si no se eleva al saber absoluto."15 Una afirmación semejante se conecta, algunas páginas más abajo, con esta otra, que contiene hondos ecos de aquel primer Fichte prekantiano que buscaba la religión del corazón: "Ha dicho: "la vida eterna es que te conozcan a tí y al que tú has enviado"; es decir, en nuestro lenguaje: la ley originaria y su imagen eterna; meramente que conozcan; y en verdad este conocimiento no sólo conduce a la vida, sino que es la vida."16

A tenor de estas expresiones, y salvo que dudemos de su honestidad, cosa que nadie que se haya acercado a él puede hacer, Fichte parece convencido de que, en efecto, la contraposición entre vida y especulación, tal como él mismo la recogía en las Respuestas de 1799 era sólo aparente. Más aún, a la luz de esos textos Fichte parece estar convencido de que la Doctrina de la Ciencia ha realizado de un modo ejemplar lo que ya en sus años jóvenes presentaba como la idea del hombre completo, y precisamente porque ha sabido conciliar la teoría y la praxis. Sus manifestaciones al respecto, el especial énfasis que pone en la afirmación de la vida, están sin duda motivadas por la polémica con Jacobi, pero no se explicarían sin esa convicción previa, sin la cual jamás le hubiera dado Fichte la importancia que le dio.

En ese sentido es desde luego posible afirmar que la noción misma de la vida condensaría el núcleo de esa unidad orgánica que es la obra de Fichte en su conjunto, un núcleo que podría resumirse en estas palabras de la Doctrina del Estado de 1813: "nada inmóvil, nada de lo que está en reposo y muerto, puede entrar en el círculo de lo que llamo filosofía. Ella es sólo acto, movimiento y vida. No encuentra nada, sino que lo hace nacer todo ante nuestro ojos"17. Y si hubiera que resumir entonces el elemento común de esa filosofía primera en relación a las distintas presentaciones de la vida, habría entonces que admitir que Fichte se aferra a su comprensión de la vida como actividad, razón por la cual la aproximación científica contiene en sí misma la vida, y no sólo la contiene, sino que la realiza en su modo más elevado en los seres finitos. Es la energía contenida en la noción de la intuición intelectual del periodo de Jena, sólo que reelaborada, la energía de la agilidad que reclama una y otra vez a sus oyentes, la misma que pedía en la Doctrina de la ciencia nova methodo, la

15 FW, X, 290. Doctrina de la ciencia. Exposición de 1804. Traducción de Juan Cruz Cruz, Pamplona, 2005 , p. 239.

16 FW, X, 291. Traducción española citada, p. 240.

17 Cita que utiliza Jean-Christophe Goddard, para quien todavía al final de su vida, en 1813, Fichte no hace sino repetir lo mismo que había defendido frente a los representantes del trono y del altar en 1800 (y a comienzos de los 90, es decir, en pleno proceso revolucionario, añadimos nosotros). Cfr., J.Ch Goddard. Croyance et intelligence dans la doctrine $d L^{\prime}$ Etat, p. 11. Disponible en la web http://perso.cpdr.ucl.ac.be/maesschalck/textesdeJ-ChGoddard.pdf 
misma que está ya presente en el primer sistema del 94, y la misma que le permite insistir en que la Doctrina de la Ciencia es el primer sistema de la libertad, la misma que años atrás le había permitido corregir el juicio del público sobre la Revolución francesa y reivindicar la libertad de pensamiento en los escritos políticos del93. Pero si los distintos desarrollos del concepto de vida que Fichte realiza a partir de la polémica del ateísmo son los depositarios de esa energía que estaba ya presente en 1794, o en los escritos políticos del 93, si, por así decirlo, reproduce el gesto contenido en la corrección del término Tatsache como Tathandlung en el momento fundacional de la Reseña de Enesidemo, entonces, incluso a pesar de los cambios terminológicos, es porque Fichte se mantiene fiel al que fue su propósito inicial, el detrasladar la dimensión práctica al principio de la filosofía y del sistema.

Sin embargo, el territorio en el que sitúa la disputa Jacobi es en realidad otro, como expresa muy bien Hegel en Fe y saber ${ }^{18,}$ un escrito que se elabora casi al calor de la disputa reciente, y ese problema es el de vida como experiencia o vivencia individual, cuya máxima expresión es el sentimiento, al que se vincula estrechamente la fe y la fe en un Dios personal y transcendente. Para Jacobi la vida entendida en esos términos y Dios mismo son sin más inasibles para la filosofía especulativa. Fichte asume de hecho inicialmente la distancia entre la vida como mundo de la vida, podríamos decir, y la propia definición de divinidad frente a la especulación. Considera ambas como inconcebibles en la ya citada frase de 1799: "Vivir es propiamente no-filosofar, filosofar es propiamente no-vivir"19. Sin embargo, cree que es posible asumir esa premisa de Jacobi en su propia filosofía, y precisamente lo cree por la estrecha relación que él mismo ha establecido entre la divinidad y la dimensión práctica de lo humano, lo que es lo mismo que decir que lo cree por la relación que ha establecido entre la vida como práctica y la noción misma de divinidad, que por lo demás es también para él incognoscible, tal como afirma Jacobi. Para expresarlo gráficamente podríamos decir que Fichte intenta ser un buen kantiano, pero pretende ser además un buen jacobiano - tal como Jacobi afirma cruelmente en su carta a Jean Paul del 16 de marzo 1800-, y piensa que, después de haber situado al sentimiento moral como verdadero fundamento de la certeza, tal como había hecho en la Ética ${ }^{20}$, el puente definitivo entre los tres, entre él mismo, Jacobi y Kant, lo puede establecer explicitando y enfatizando un elemento que además no era nuevo en su filosofía y era clave también en Kant, como lo es la fe, la misma que da el título a la tercera parte del Destino del Hombre y en respuesta directa a Jacobi.

Cabría entonces distinguir tres conceptos de vida en el interior de esa teoría de la vida, de la imagen y del concepto tal como se articulan en la presentación de la Doctrina de la Ciencia de 1804. En primer lugar estaría el concepto de vida de lo que podríamos llamar el mundo de la vida, que se correspondería con la vida individual, en segundo lugar la vida que desarrolla la propia ciencia como concepto e imagen, y finalmente la vida propiamente dicha que es una con el ser y que se llama también Dios. Pero en último término esos tres niveles de vida remiten en realidad a uno solo que es la vida propiamente dicha, es decir, la

18 Cfr., Glauben und Wissen, oder die Reflexionsphilosophie der Subjektivität in der Vollständigkeit ihrer Formen als Kantische, Jacobische und Fichtische Philosophie. Hamburg, Felix Meiner, 1962.Fe y saber. O la filosofia de la reflexión de la subjetividad en la totalidad de sus formas como filosofía de Kant, Jacobi y Fichte. Traducción de Vicente Serrano. Madrid, Biblioteca Nueva, 2000.

$19 \mathrm{FW}, \mathrm{V}, 343$.

20 GA, I, 5, 158. Ética, edición de Jacinto Rivera de Rosales, Madrid, Akal, 2005, pp. 215-16. 
vida de Dios, expresada a su vez de dos modos, bien en términos científicos en las distintas formulaciones en la Doctrina de la ciencia, o bien en su forma popular en su filosofía de la religión de $1806^{21}$. Ahora bien el núcleo común de las tres está precisamente en el concepto más elevado de vida que se recoge en la noción de vida como una con Dios o como ser, y que debe guiar prácticamente la vida individual. Y a su vez creo que éste es el depositario de la convicción fundamental de Fichte de que su sistema de Jena es el mismo, sólo que ahora debe ser explicitado. La Einsicht o intelección, así interpretada, no es más que el reflejo desde la ciencia de esa vida, que es a su vez principio. Y por eso la esencia de esa vida es quietud, a la vez que condición de toda actividad. Si esto fuera así, creo que es en ese concepto de vida, a su vez, donde se juega el análisis de lo que se llama el nihilismo y desde el que habría que considerar los ataques de Jacobi.

Ahora bien, asumiendo que la hipótesis fuera correcta, y dando un paso más, la siguiente pregunta debe dirigirse a profundizar en torno al qué de esa vida absoluta,que es ser y unidad absoluta, y ponerlo en relación con su propia trayectoria. $\mathrm{Y}$ en este punto es preciso regresar de nuevo a ese momento en el que un joven Fichte preocupado por la vida religiosa y por la búsqueda del hombre completo, es decir, lo que llama religión del corazón, expresión que sin duda nos sitúa en un territorio muy análogo al de Jacobi, se encuentra con la filosofía de Kant. Es bien conocida la conmoción que eso supone para nuestro filósofo y lo determinante que es para su propia trayectoria, hasta el punto de que se puede afirmar que ahí reside el impulso del que nacerá la Doctrina de la Ciencia. Fichte cree haber encontrado en la obra de Kant la solución a ese viejo problema que le atormentaba de algún modo, y cree haberlo encontrado mediante la razón práctica. Es la razón práctica la que le ilumina. A partir de ese momento la vida se vincula en Fichte con la razón práctica en los términos kantianos. Pero es obvio que una vinculación de esas características absorbe la vida emocional y la dimensión afectiva y las reconfigura en un nuevo complejo, que de algún modo contiene en su interior todos los problemas en torno a la vida que le plantea Jacobi y los malentendidos de ambos, pero por lo mismo una clave para interpretar las elaboraciones del Fichte posterior a la polémica sobre el ateísmo y en conversación con Jacobi.

Es preciso, pues, profundizar algo más en eso que llamo nueva reconfiguración. Lo haré de un modo muy directo mediante la afirmación de que es esa dependencia del imperativo kantiano la que va a generar inevitablemente la distancia respecto del concepto de vida de Jacobi. En la Carta a Fichte había afirmado: “¡Tenéis que someter el amor al camino seguro de la ciencia! ¡No podéis hacer otra cosa, tenéis que someter la conciencia, el espíritu más cierto, a una vida muerta de la racionalidad, hacerla muda, sorda, sin sentimientos, mediante leyes ciegas! Su raíz viva, que es el corazón humano deber ser arrancada hasta la última fibra". 22 Y un poco más abajo menciona Jacobi expresamente el imperativo categórico, al que antes había llamado cáscara vacía, como del tapaagujeros de la razón teórica al que se somete toda la vida individual. Lo que sin duda en ese momento tiene presente Jacobi es la doctrina kantiana con arreglo a la cual obtener un deber incondicionado exige prescindir de las contingencias individuales, porque de lo contrario se caería en la heteronomía ${ }^{23}$, en definitiva, exige prescindir de las emociones.

${ }^{21}$ Cfr., FW, V, 471-72.

22 Carta a Fichte. Edición española citada, p. 515.

23 "En la independencia de toda materia de la ley (a saber, de un objeto deseado) y al mismo tiempo, 
Cualquiera que medite en torno al proceso de formación y a la estructura de una norma, sabe que ésta es siempre correlato de una prohibición y que, por tanto, un deber incondicionado es también el correlato de una prohibición universal, es decir, la de no considerar moralmente, como criterio para la acción, la dimensión afectiva o empírica, la decisiva para Jacobi, para quien ésa la única dimensión de la vida. Ciertamente tanto para Kant como para Fichte ese algo negativo tiene una importante traducción positiva, que es la libertad, y además sabemos que es en ella en la que Fichte hará descansar la condición de la vida moral de los seres finitos. Es en este punto donde se sitúa el núcleo último de la disputa y los malentendidos en torno a la expresión vida entre Fichte y Jacobi. Para Jacobi la libertad no está "en la facultad de los silogismos (que pueden compararse con la facultad de la mitad de unas tijeras o de unas pinzas), sino de las convicciones; en la facultad de un afecto inmodificable y que domina sobre todas las pasiones. Cuando me baso en la palabra de alguien, no tengo tanto en cuenta su pura razón como el movimiento de sus labios y el sonido de su boca: me fío de la palabra de ese hombre y de su libre voluntad. Lo que me da certeza es su sensibilidad, su gusto, su temple y su carácter"24. Aunque Jacobi no defiende aquí, como harían las éticas eudaimonistas, que la razón sea esclava de las pasiones, hace descansar sin embargo todo el aparato emocional en un afecto fundamental al que asigna gobernarlas y que es la raíz misma de la ética, pero que para él tiene que ver con el temple, con el gusto, con la sensibilidad. Sabemos que ese afecto fundamental depende en Jacobi de la transcendencia y de la divinidad transcendente. También Fichte, como Kant, se refiere a un afecto fundamental, de manera especialmente nítida y explícita enlo que llama el afecto de respeto a la ley moral, en el parágrafo 15 de la $E_{t i c a}{ }^{25}$. Y si es cierto que después de la polémica, el mero respeto a la ley moral es considerado un punto de vista inferior ${ }^{26}$, no lo es menos que la forma superior de la ética, la ética suprema se expresa, sin embargo, de manera más nítida, entendida en sentido religioso, en términos de amor: "la beatitud misma consiste en el amor y en la satisfacción eterna del amor y es inaccesible a la reflexión"27. No es dudoso que Jacobi desconozca esa noción de la filosofía de Fichte, procedente a su vez de la filosofía de Kant, y sin embargo su afirmación de ese afecto fundamental se presenta en la Carta explícitamente en contraposición directa a ambos. La cuestión de la vida y de la diferencia entre las respectivas concepciones de Jacobi y Fichte se juega pues en el interior de eso que llamamos afecto.

Y para ello es necesario de nuevo acudir a la fuente, al imperativo kantiano. Como he afirmado, el imperativo no es desde el punto de vista de su génesis algo positivo, sino sólo la respuesta de Kant a la aporía característica de la modernidad desde el punto de vista moral, la de construir una moral no eudaimonista ni basada en la divinidad, es decir, no basada en ninguna de las formas conocidas de la heteronomía. Desaparecido el ser entendi-

sin embargo, en la determinación del albedrío por medio de la mera forma legisdladora universal, de que una máxima tiene que ser capaz, consiste el principio único de la moralidad“. Crítica de la razón práctica, parágrafo 8 , teorema 4.AA, V, 33. Versión española en Crítica de la razón práctica. Traducción de Manuel García Morente Madrid, Espasa-Calpe, 1981, p. 54.

24 Carta a Fichte. Edición española citada, pp. 535-36.

25 GA, I, 5, 152 y ss. Ética. Traducción de Jacinto Rivera de Rosales, Madrid, Akal, 2005, p. 210.

26 Cf., FW, V, 467-68 y 501 y ss.

27 FW, V, 549. 
do como noción a partir de la cual obtener el bien, y a partir de ahí el deber, la propuesta kantiana es acudir directamente, como sabemos, al concepto de deber, obtener directamente el deber sin la mediación de un ser. En ese sentido el deber moral kantiano está cargado, si se me permite la expresión, de una sombra ontológica, que es la ausencia de ser (que es lo que de algún modo denuncia también Jacobi desde su empirismo y que se refleja en la acusación de nihilismo), pero una sombra que desde el punto vista positivo que buscamos tiene que ver con el principio constitutivo de la modernidad como acción, como potencia, diría Spinoza, como voluntad de poder dirá Nietzsche casi un siglo más tarde. Si es posible encontrar un deber universal, que es lo propio del universo moral, según piensa Kant, y si ha de irse más allá del horizonte del puro deseo en el que, según Hume, la razón es y será esclava de las pasiones, entonces ese deber ha de asentarse fuera del ser del deseo propio de la razón prudencial, de la razón práctica que Kant critica. ${ }^{28}$ Es ese ser del deseo natural y empírico el que constituye, siquiera negativamente, el horizonte ontológico frente al que busca Kant un deber ser racional. Y por eso mismo, el deber ser es el que neutraliza el deseo y hace posible que el sujeto encuentre un límite para sus acciones, si asumimos que en la modernidad no es posible encontrar un límite inmanente, como sí lo había, por ejemplo, en la ética de Aristóteles. Por tanto, si la moral no quiere ser heterónoma, ha de construirse entonces a partir de un límite, de una prohibición, noaccesible al conocimiento y cuyo único indicio para el ser racional descansa para Kant en la creencia y adopta esa forma de sentimiento de respeto por la ley moral.29

Pero, una vez más, si la hipótesis es correcta, y creo que nadie negará que los dos elementos que la sustentan, a saber que la filosofía de Fichte se asienta sobre el imperativo moral kantiano y que éste excluye por definición la posibilidad de asentarlo en la vida emocional como afecto fundamental a partir del cual obtener las máximas, podemos decir entonces que hemos encontrado un punto donde situar y dirimir finalmente el conflicto entre Fichte y Jacobi en torno a la vida. No es casual que todas estas cuestiones salgan a la luz en el contexto de una polémica sobre el ateísmo, porque el afecto fundamental del que habla Jacobi sólo puede combinar su función moral con la idea de un Dios transcendente, de eso incognoscible, de esa creencia y de ese salto mortal. Si el territorio al que Jacobi llevó la polémica en torno a la vida es el de la vida individual, emocional, y por tanto el del sentimiento, pero el sentimiento empírico, considerado como Tatsache, podríamos decir, y no como Tathandlung, es precisamente porque para él esa vida emocional e individual contiene ya en sí lo inconcebible, la divinidad transcendente respecto de la cual sólo cabe la creencia.

En el caso de Jacobi la limitación y el afecto se vinculan, pues, estrechamente a la asunción de un realismo empírico que va de la mano de la transcendencia, es decir, inseparable de que la divinidad aparece como lo absolutamente otro inaccesible. Eso quiere decir que la vida emocional en el plano empírico se coordina con una dimensión moral situada en el plano transcendente. Por tanto, el realismo de Jacobi nos sitúa directamente en el universo del deseo moderno, pero a la vez, en el sentimiento de la divinidad transcendente que configura una moral heterónoma y que, por ello, ha salvado ya el problema al que debe enfrentarse Kant y que hereda Fichte. En Fichte el mundo individual afectivo, la vida de Jacobi,

28 "Por consiguiente habremos de elaborar, no una crítica de la razón pura práctica, sino de la razón práctica en general". AA, V, 15-16. Edición española citada. p. 28.

29 AA, V, 76. Edición española citada, p. 110. 
en la medida en que no puede recurrir a una divinidad transcendente, tiene la difícil tarea de instalar en su interior un principio inmanente y a la vez ajeno a la naturaleza, es decir, ajeno la vida emocional propiamente dicha, pues el sustrato emocional, que en Aristóteles o en Hume son la base de la vida ética, en cada uno a su modo, tiene que ver con la dimensión natural de lo humano, con las pulsiones, con lo que llaman Fichte y Kant el deseo inferior. Sabemos que en el caso de Kant eso se hace mediante un expediente hipotético que se completa mediante el juego de los postulados de la razón práctica. ${ }^{30}$ Pero precisamente la tarea de Fichte es convertir esa instancia en principio de la filosofía. Y es obvio que esa tarea decide su propia obra, pero por lo mismo también su evolución a partir de la polémica del ateísmo, donde no le valdrá ya pasar de una metafísica de las costumbres a un ética, paso que él mismo había dado en Jena ${ }^{31}$, sino que ese vacío querrá ser llenado con la idea de Dios como ser y vida, cuyo significado investigamos ahora, precisamente porque la vida es portadora de lo pensado en la práctica y es lo que se siente obligado a desarrollar tras la polémica. En la medida en que la condición moral tiene la misma dimensión de transcender la finitud del sujeto, formalmente y funcionalmente Fichte no ve tanta distancia respecto de Jacobi, y en ese sentido nada más natural que lo pensara como vida y que tratara de desarrollarlo en esos términos.

En el periodo de Jena Fiche se había ocupado intensamente en torno a la noción del sentimiento, que era, como en Jacobi, expresión de la finitud y que en ambos dependía de una instancia que está más allá y de la que el sentimiento es indicio, sólo que en Fichte ese límite era deducido transcendentalmente, es decir, en el ámbito de la reflexión y siempre dependiendo como de su condición última de lo moral. De ahí que el sentimiento jugara un papel decisivo en su filosofía en todas sus presentaciones y más allá de las diferentes roles y significados que le asignó en cada una de ellas, hasta el punto de que constituye la conciencia misma de la realidad, la condición de fuente de la propia conciencia y de toda vida ya desde el escrito Sobre el concepto de la doctrina de la ciencia, y lo seguirá siendo en la formulación nova methodo que culmina el periodo de Jena. No es mi objetivo aquí, ni sería posible, hacer un seguimiento de las modulaciones que el término sentimiento tiene en cada una de esas presentaciones mencionadas, de las distintas figuras en las que se articula ${ }^{32}$, pero creo que es necesario destacar el rasgo común que permite diferenciarlo de Jacobi, que no es otro que su dependencia respecto del principio moral kantiano. Ya se presente directamente como sentimiento vinculado a la ley moral, o ya se presente en su función teórica en sus distintas figuras, es siempre dependiente del imperativo moral, que aparece como un metacampo superior que además asegura la coordinación entre teoría y praxis ${ }^{33}$ de la que partió Fichte.

30 Cf., AA, V, 132. Edición española citada, p. 184.

31 "Si únicamente se mira a la facultad superior de desear, entonces se obtiene simplemente una metafisica de las costumbres, que es formal y vacía. Sólo mediante las unión sintética de esa facultad con la inferior se obtiene una ética, que ha de ser real”. GA, I, 5, 126. Ética, edición citada, p. 181.

32 Una exposición muy ordenada y casi exhaustiva, al menos hasta la presentación de 1801, puede encontrarse en Petra Lohmann, Der Begriff des Gefühls in der Philosophie Johann Gottlieb Fichtes, Fichte-Studien. Suplementa, 18, Ámsterdam, Rodopi, 2004. En español hay una rigurosa exposición del tema en Jacinto Rivera de Rosales "La relevancia ontológica del sentimiento en Fichte". En V. López Domínguez, Fichte, 200 años después. Madrid, Editorial Complutense, 1996, 45-73.

33 Cf., P. Lohmann, o.c., p. 73. 
Llegamos así al punto dirimente entre ambos, que no puede ser otro que el del carácter inmanente o transcendente de eso que, estando más allá de la finitud, es indicador de la misma y que se expresa en el sentimiento. En un principio transcendente, como el de Jacobi, tanto el criterio moral como el epistemológico están fuera de la naturaleza y dependen de una instancia suprasensible, que a su vez en esa medida es creadora, como fundamento último del límite y del afecto, razón por la cual en Jacobi la condición finita e individual y el sentimiento son indicadores de Dios mismo más allá de la filosofía. Sabemos que para el Fichte de Jena esa instancia es el imperativo moral, o por mejor decir el orden moral del mundo y como tal inmanente. Pero, una vez más allá de esa diferencia, que es, por lo demás, la que se ventila en la polémica, hay una coincidencia formal o funcional, el carácter no conceptuable de ese principio, o si se prefiere, el hecho de que ese principio que da sentido a la reflexión y es su fundamento no puede ser él mismo objeto de reflexión y, por lo tanto, en esa medida es funcionalmente coincidente con el afecto fundamental que en Jacobi da cuenta de la fuente de toda vida: el Dios creador, personal y transcendente. La referencia a lo incomprensible o inconcebible es entonces el desarrollo formal de lo mismo que Fichte había tratado de explicar en el periodo de Jena, la aspiración hacia una instancia inalcanzable por definición, pero que como tal debe guiar la vida finita toda. Por eso la descripción del sentimiento del anhelo de la Fundamentación del 94 como "vehículo de todas las leyes prácticas y la manifestación originaria de la aspiración" 34 , un sentimiento de un impulso moral que no descansa y nos ordena someter la naturaleza, encuentra su perfecto correlato, después de la polémica, en esa aspiración a acercarse a la voluntad divina ante la cual se debe nihilizar el yo individual para "su entrada en la vida espiritual" 35 . Ese anhelo hacia lo eterno, que se presenta ahora en una metafísica del ser, es el correlato del mismo impulso que en Jena buscaba subordinar todo a la prosecución infinita del yo empírico hacia el Yo puro, a fin de someter a él los sentimientos. Desde el punto de vista del sujeto finito no cabe duda de que el estado en cuestión es un afecto, ${ }^{36}$ pero un afecto que tiene la particularidad de pretender rebasar la misma noción de afectividad, es decir, de prometer la superación de todo límite, una promesa que sabemos que en Fichte no es alcanzable por definición, pero cuya tendencia rige toda la vida moral. Ese afecto y esa tendencia que rige la vida moral es el mismo que ahora debe llevarnos a la vida bienaventurada. Y como tal, en efecto, no elimina la naturaleza desde el punto de vista epistemológico, ni es creador del mundo empírico como pretendía Jacobi, o como siguen creyendo todavía algunos lectores, sino sólo su condición de posibilidad, una condición transcendental compatible con una concepción de la moral, pero sí convierte a la naturaleza en un objeto sometido a esa instancia, a ese afecto, en un instrumento a su servicio.

Si uno aparta momentáneamente la mirada de Fichte y busca analogías, siquiera formales, en la historia de la filosofía moderna, descubre que ese afecto se parece en realidad mucho a la noción de deseo de Hobbes, en principio ilimitado, o al conatus spinozista, o incluso a la voluntad de poder de Nietzsche, en los términos en los que lo define Heidegger

\footnotetext{
34 FW, I, 304.

35 "Diese Selbstverninchtung ist der Eintritt in das höhere [Leben]", FW, V, 518.

36 El sentimiento de la vida de la existencia moral es el nombre que le da Traub. Traub, H., Vollendung der Lebensform. Fichtes Lehre vom seligen Leben als Theorie der Weltanschauung und des Lebensgefühls, En Fichte-Studien, 8, p. 186.
} 
como voluntad de voluntad. Pero se parece sólo en su progresión, en su carácter ilimitado, y se separa de éstos en que lo anclado en ellos en el deseo empírico, lo encontramos en Fichte como el reverso, la contrafigura de ese deseo, la de una progresión constante hacia la anulación de ese deseo. Como en el caso de la voluntad de poder de Nietzsche no tiene objeto propiamente dicho. La expresión heideggeriana de voluntad de voluntad ${ }^{37}$ como definidora de la voluntad de poder en Nietzsche y a la vez culminación nihilista de la metafísica de Occidente, no resultaría nada desajustada aquí, porque nosotros sabemos que en el Fichte de Jena la raíz última de la conciencia misma es la aspiración del Yo a llegar a un acuerdo con respecto a sí mismo, y que por tanto tiende al infinito, un Yo cuya esencia es la libertad, y que se asienta entonces sobre esa voluntad pura, el mismo movimiento en que consiste, en el Fichte de Berlín, la nihilización del yo individual como puerta de entrada en la vida espiritual. Por retomar, entonces, una vez más la figura del cubo invertido del spinozismo usada por Jacobi para caracterizar la filosofía de Fichte, ${ }^{38}$ pero aplicada en este caso a Nietzsche, parecería como si en el fondo los dos extremos opuestos, el cubo del nietzscheanismo y el del fichteanismo acabaran coincidiendo, el uno desde un acendrado naturalismo y el otro desde una figura transcendental o metafísica, lo cual desde este punto de vista nos es por ahora indiferente.

Claro que ese supuesto nihilismo afectivo de Fichte arroja resultados y consecuencias muy diferentes en comparación con el nihilismo de Nietzsche y está lleno de una grandeza y de una utilidad de la que carece el nietzscheano. Si en el caso de Nietzsche ese resultado se condensa en el delirio de un deseo ilimitado, el nihilismo afectivo de Fichte representaría la metafísica más acabada de la tal vez hoy única convicción moral que conservamos en Occidente: la de los derechos humanos entendidos como posibilidad de pensar el límite de una voluntad de poder absoluta, como la expresión positiva de un límite universal al deseo ilimitado de los sujetos. Como tales los derechos humanos expresan un deber universal, incondicionado y general en el que la libertad de cada cual es lo único sacro. Ese deber universal e incondicionado tiene su expresión última y general en el imperativo categórico, que a su vez se expresa en las distintas esferas de acción de los sujetos a respetar, dando así lugar a los distintos derechos particulares, como la vida, la libertad de pensar, o la integridad física y moral, entre otros, pero todos ellos reconducibles a la persona moral, a la dignidad y a ese fin en sí mismo único que está en la base de todas las declaraciones de derechos conocidas.

Sin embargo, es cierto que una ética de los derechos humanos queda muy lejos de las viejas éticas premodernas, y no ofrece ningún criterio para cada individuo en orden a qué es lo mejor para, desde la propia libertad, alcanzar la felicidad, ese objeto que ha guiado la ética desde Aristóteles. Una ética de los derechos humanos roza la ética entonces, en tanto prohibición y en tanto norma entendida como reverso de la prohibición, pero no puede consumar la ética ni resolver la antinomia de la razón práctica kantiana. Dicho en otras palabras: no dice nada de la vida feliz. De ahí que en su Ética, la obra que debería completar el vacío de la moral kantiana, Fichte no puede ni quiere ofrecer un verdadero catálogo de virtudes en el

37 Cfr., Nietzsche: Der europäische Nihilismus. Pfulligen, Neske, 1961, p. 46. Hay edición en español en Nietzsche. Traducción de J.L.Vermal, Barcelona, Destino, 2000, Entre otros lugares, V. I, pp. 49 y 50 .

38 Cfr. GA, III, 3, 226-27. Edición española citada, p. 506. 
sentido de la vida feliz, en el sentido de la Glückseligkeit, entendida como la felicidad vinculada a la vida natural, que no es propiamente moral, esto es, de una felicidad basada en las disposiciones anímicas y afectivas a partir de las cuales el individuo pueda gestionar sus emociones. Por eso, lo que tendrían que haber sido virtudes se resumen finalmente en un catálogo de deberes ${ }^{39}$ que, bien mirados, son una transferencia al interior del individuo de las principales matrices de los distintos derechos humanos en cuanto deberes universales e incondicionados relativos a la libertad formal de los otros y en función de las esferas de acción a proteger. Como deberes son entonces un trasunto del bien protegido en cada uno de los derechos particulares y todos ellos subordinados a la posibilidad misma del respeto a la ley moral incondicionada. O como Fichte afirma en el comienzo del parágrafo 22 de la Ética: "El fin último de todas las acciones del buen hombre ético en general y en particular de todos sus actos hacia el exterior se puede resumir en esta fórmula: él quiere que la razón, y sólo ella, domine en el mundo sensible"40. Así, el deber de la autoconservación no es más que el trasunto a la vida individual del derecho a la vida, el deber de cuidar del propio cuerpo y todo lo que le acompaña un trasunto del derecho a la integridad física y moral y del derecho a la propiedad, un instrumento más entonces para asegurar y hacer posible la vida moral, aderezado todo ello con una serie de deberes especiales en función del estado de cada cual y de las profesiones, nuevos deberes particulares que son, o bien un desarrollo asociado a los anteriores, o bien un catálogo de formas morales asociadas a la época y al orden social, pero en ningún caso virtudes propiamente dichas.

Pero, nada más coherente que esa exclusión acerca de la felicidad, pues tal exclusión no es sino un corolario de la subordinación de lo sensible al imperativo moral que es el rasgo más distintivo de ese nihilismo afectivo. Sin embargo sabemos que Fichte no se conformó con eso, es decir, con presentar en forma de virtudes un conjunto de deberes que derivan del imperativo moral. En su filosofía de la religión ofrece un contenido que aparentemente parece ir más allá, y precisamente ese contenido es el que da nombre a la obra. La Seligkeit no será ya el puro vacío de una prohibición presentada positivamente en forma de deberes, sino que pretende ofrecer un contenido positivo de ese ámbito.

Y nada más natural que su respuesta en esa dirección, en la que completa la ética y amplía la del período de Jena, esté contenida entonces en un escrito sobre la religión y que lo esté además después de la polémica sobre el ateísmo, es decir, de las profundas transformaciones articuladas en torno a la vida motivadas especialmente por el reproche de Jacobi que estamos analizando. Decíamos más arriba que la solución de Fichte frente a la propuesta de Jacobi era la de buscar una dimensión que transcendiera la vida afectiva pero sin descansar ya en una divinidad transcendente. En 1804 Fichte ya había elaborado, más allá de los deberes, una nueva fórmula para esa instancia y lo había llamado ser y uno con la vida, vida o verdadero absoluto en que se absorbe todo ser $^{41}$, un ser que se expresa en una imagen, es decir, que se expresa en la existencia y en la reflexión. En cierto modo el desarrollo de esa instancia, desde el punto de vista de la ética en su sentido más profundo, no podía ser

\footnotetext{
${ }^{39}$ A ello está dedicada la sección tercera del capítulo 3 de la Ética del 98. GA, I, 5, 229-317. Edición española citada, pp. 282-360.

40 GA, I, 5, 246. Edición española citada, p. 298.

${ }^{41}$ FW, X, 174. Doctrina de la Ciencia de 1804, edición citada, p. 125.
} 
sino una teoría acerca de ese estado o condición que permite acercarse a la plenitud de esa vida: la Seligkeit como aproximación a esa instancia inmanente que ocupa el lugar de Dios, pero sin serlo, al menos sin serlo en el sentido transcendente de Jacobi. Y nada más natural que lo desarrolle en una doctrina sobre la religión. Pero esa religión no es desde luego la de Jacobi. Y creo que ahí se juega en parte un importante criterio a tener en cuenta respecto del grado de ruptura o no entre el Fichte de Jena y el posterior, pero también en relación con ese contenido positivo cifrado en el término Seligkeit, y por tanto con la cuestión del nihilismo.

Tanto en la Doctrina de la ciencia de 180442 como en la Iniciación a la vida bienaventurada Fichte rechaza de manera nítida y contundente el concepto de creación a partir de la nada, a la que considera en la sexta conferencia "el error fundamental absoluto de toda falsa metafísica, de toda falsa religión" 43 . Pero de este error, que atribuye al paganismo y al judaísmo, se aparta Fichte en su interpretación del cristianismo a partir de su lectura del evangelio de San Juan y de su consideración del Logos como principio eterno, para traducir inmediatamente ese Logos, en cuanto existencia del absoluto, como conciencia y reflexión. Nada puede ser en ese sentido más opuesto a la noción transcendente de Jacobi. En las Cartas sobre la doctrina de Spinoza había establecido el criterio de demarcación de la divinidad en su carácter personal, y había recordado, en palabras de Lessing, la fórmula que condensaba el ateísmo: "de la nada nada surge”. Una fórmula muy análoga a la que Fichte usa para evidenciar su rechazo de la creación: "En Dios y de Dios nada deviene y no se produce nada" 44 . Una fórmula que, sin embargo, no se puede interpretar, desde luego, como una aproximación a Spinoza, pues la cifra más evidente del abismo que le separa de Spinoza está en la, para Fichte imposible y abominable, ecuación spinozista entre Dios y la naturaleza.Pero tampoco cabe interpretarla como un verdadero abandono del carácter transcendental de su propia filosofía. Al contrario, ha de interpretarse como una confirmación de que es la Seligkeit la que debe dar un contenido a esa ética suprema, un contenido que ha de completar la ética vacía y negativa de Kant y a la suya propia, como él mismo la caracteriza al referirse a su concepción ética de Jena, es decir, a la ética entendida negativamente y a la que yo he calificado como el reverso de los derechos humanos entendidos como prohibición universal. El ser como lo incognoscible y absoluto sigue sin poder alcanzarse, como ya ocurría en la Doctrina de la ciencia de Jena respecto del Yo absoluto, sigue siendo fundamento y condición de posibilidad de todo lo demás, vida que se trasluce en la vida de la reflexión, que explica el devenir sin serlo, principio inmanente, entonces, y de ahí su quietud como vida que se expresa en el saber. El que se eleva hasta ahí, hasta esa comprensión y la genera genéticamente, el que alcanza esa Einsicht, roza esa quietud y la descubre en su interior como Seligkeit.

Pero para ello, como ocurría en el Fichte anterior, ha debido someter todos los afectos a ese afecto superior que es el inverso de la voluntad de poder, y el absoluto aparece entonces como aquella instancia que era ya el imperativo moral, no transcendente, pero transcendiendo sin embargo la naturaleza y el mundo de la vida individual: la otra cara de la voluntad de poder en un universo ya nihilista, esa época a la que se refiere de modo reiterado en Berlín y que en Los caracteres de la Edad contemporánea considera "la perversión consu-

\footnotetext{
42 Cfr. FW, X, 236. Edición española citada, p. 187.

$43 \mathrm{FW}, \mathrm{V}, 479$.

$44 \mathrm{FW}, \mathrm{V}, 480$.
} 
mada" 45 , que en cierto modo sigue siendo la nuestra, caracterizada, podríamos decir, por el predominio de la voluntad de poder propio de la libertad formal descrita en la Ética. En ese sentido la Seligkeit se parecería a la felicidad que Aristóteles describe en el libro X de la Ética a Nicómaco, pero un Aristóteles donde el motor inmóvil no puede entenderse ya desde la divinidad transcendente ni desde la naturaleza. De ahí la grandeza del esfuerzo de Fichte, de su hazaña, la de pensar una metafísica que no parta ni de Dios ni de la naturaleza, algo que le permite afirmar a él, y a nosotros con él, que, a pesar de todo, aunque Dios haya muerto, no todo está permitido.

Queda, sin embargo, la pregunta de si era realmente necesario pagar ese precio, si era necesario degradar la naturaleza a la condición de mero instrumento, y de si ese precio no es demasiado alto, y sobre todo la de si al hacerlo no está en realidad asumiendo la premisa implícita de la modernidad, de esa época de la que él mismo se lamenta amargamente en los Caracteres de la Edad contemporánea, una época que ha hecho de la voluntad de poder su principio y que lo ha trasladado además a la propia naturaleza, a su imagen y semejanza. Porque hubo un tiempo, sin embargo, en el que la naturaleza contenía para los humanos el principio de la justicia, al que algunos llamaron Logos. Queda la duda entonces de si, más allá del sueño poético de Hölderlin, es posible para nosotros lo humanos del siglo XXI construir una ética que no se quede en el imprescindible pero empobrecedor horizonte de los derechos humanos, de si es posible una ética en sentido pleno, y de si la naturaleza puede todavía decirnos algo, una vez liberada del férreo dominio al que la ha sometido la voluntad de poder en la modernidad. Un férreo dominio del que, en alguna medida, la filosofía de Fichte no dejaría de ser un reflejo más, incluso a su pesar.

Vicente Serrano

Universidad Austral de Chile

vicente.serrano.marin@gmail.com

45 R. Lauth, El concepto de historia en los "Discursos a la nación alemana". En Anuario filosófico de la Universidad de Navarra, 1979, XVII, p. 67. 